\title{
Sensory, Physico-Chemical and Nutritional Properties of Gluten Free Biscuits Formulated with Quinoa (Chenopodium quinoa Willd.), Foxtail Millet (Setaria italica) and Hydrocolloids
}

\author{
V. Thejasri ${ }^{1 *}$, T.V. Hymavathi ${ }^{1}$, T.P. Pradeepa Roberts ${ }^{2}$, \\ B. Anusha ${ }^{1}$ and S. Suchiritha Devi ${ }^{1}$ \\ ${ }^{1}$ Department of Foods and Nutrition, ${ }^{2}$ Millet Processing and Incubation Centre, Professor \\ Jayashankar Telangana State Agricultural University, Rajendranagar- Hyderabad, 500030, \\ Telangana, India \\ *Corresponding author
}

\section{A B S T R A C T}

Keywords

Gluten free, Hydrocolloids, Quinoa, Foxtail millet, Biscuits, Nutritional quality, Sensory quality, Physico- chemical characteristics.

Article Info

Accepted:

19 June 2017 Available Online: 10 August 2017
Quinoa and foxtail millets are naturally gluten free grains are rich in many nutrient and health benefiting compounds. Gluten free (GF) biscuits were prepared from both the grains, by employing hydrocolloids and the sensory, physico- chemical and nutritional properties were assessed. Compared to GF biscuits, control wheat biscuits (WHB) received higher scores. Addition of combination hydrocolloids improved the sensorial quality of both foxtail millet biscuits (FMB) and quinoa biscuits (QAB). Addition of GG XG at $1 \%$ significantly improved the color, taste, texture and flavor of FMB relative to FMB control. While addition of TG $\mathrm{XG}$ at $1 \%$ reduced hardness, darkness and improved taste in QAB. Application of combination hydrocolloids improved the weight, thickness and diameter and decreased the spread ration significantly $(\mathrm{p}<0.05)$. Compared to the wheat biscuits both the GF biscuits had significantly $(p>0.05)$ higher nutrients that are studied.

\section{Introduction}

Food allergies and food intolerances are a growing public health concern causing higher consumer demand of products that are tailored to meet special dietary requirements. Celiac disease (CD) is an inflammatory disease of the small intestine and is triggered by gluten proteins from wheat, barley and rye. Its prevalence is 1:100-1:200 in any population throughout the world (Schuppan et al., 2009).
People on a strict gluten-free diet are frequently undernourished since their rapidly available-energy intake, which in the western diet is largely taken from wheat-based foodstuffs, is reduced. Owing to the amazing growth of the gluten free (GF) market, it is pivotal to pay attention to nutritional quality in the development of GF foods and consequently to improve it by adopting several strategies. 
The gluten replacement in bakery products represents a major technological problem due to structure building properties. Gluten removal weakens dough structure to develop properly during kneading and baking (Gallagher, 2002). However, unlike pasta and bread, gluten network in cookies and biscuits requires minimum development (Schober et al., 2003). The texture of baked biscuits is primarily attributed to starch gelatinization and super cooled sugar rather than a protein/starch structure (Gallagher, 2002). Nevertheless, commercial gluten-free biscuits are generally based on pure starch, thus have poor organoleptic quality (Schober et al., 2003).Inadequate fiber intake from many GF foods had been reported as they are made with starches and /or refined flours with low content in fiber (Thompson, 2000). Studies on the nutritional composition of processed gluten-free demonstrated that they have high levels of lipids, sugars and salt. Subjects with celiac disease tend to compensate for the restrictions of a gluten-free diet by eating foods containing high levels of fat, sugar and calories which leads to an excessive consumption of total fats and saturated fats (Saturni et al., 2010). Since gluten plays a limited role in defining the process ability and end product quality of biscuits, it can be complemented through some alternate flours in various combinations (Rai et al., 2011) which are rich in nutrients to increase the nutrient content of GF products.

Foxtail millet [Setaria italica (L.)] is an important millet grain, grown in various parts of India. It grows well even under adverse agro climatic conditions. Foxtail millet has good nutritional profile and is comparable to staple cereals as rice and wheat in terms of protein, fiber, minerals and vitamins (Thathola et al., 2010). Foxtail millet is a good source of protein $(12.3 \mathrm{~g} / 100 \mathrm{~g})$ and dietary fiber $(14 \mathrm{~g} / 100 \mathrm{~g})$ and dietary fiber minerals (3 $\mathrm{g} / 100 \mathrm{~g})$ and phytochemicals
(Malleshi, 1986), В carotene (126-191 $\mu \mathrm{g} / 100 \mathrm{~g})$ (Goudar et al., 2011). Quinoa (Chenopodium quinoa Wild.), which is considered a pseudo-cereal or pseudo-grain; it is highly nutritious due to its outstanding protein quality and wide range of minerals and vitamins. It has been recognized as a complete food due to its protein quality. The protein content of quinoa ranges between 13.81 and $21.9 \%$ depending on the variety. Quinoa starch has physicochemical properties (such as viscosity, freeze stability) which give it functional properties with novel uses (Vandana et al., 2015). Although these grains are highly nutritious very limited products are being manufactured due to their physical properties viz no gluten in them.

Hydrocolloids are one of the most important ingredients in developing gluten free formulations for improving the texture and appearance of the final products (Mariotti et al., 2009). In addition to the obvious benefits of taste, texture, mouth feel, moisture control, and water mobility, they also improve the overall product quality and stability by withstanding the demands of processing, distribution, and final preparation (Xue et al., 2009). The effect of the addition of various hydrocolloids on the quality of gluten-free cookies prepared from buck wheat flour has been studied by Kaur et al., (2013) who showed that buckwheat addition significantly improved the sensory scores and overall acceptability of cookies. Sharadanat et al., (2003) reported that gum acacia increased the loaf volume and improved bread characteristics such as texture, cell wall structure and softness. However, there was no available published data on the quality of the gluten free biscuits produced from quinoa and foxtail millet by employing hydrocolloids. Hence the present investigation was taken up with an aim to understand the properties of the gluten free biscuits prepared from nutrient dense quinoa and foxtail millet. 


\section{Materials and Methods}

Foxtail millet was procured directly from farmers, Quinoa was procured from Inner Being \& Wellness Pvt. Ltd- Hyderabad on gratis. Guar gum (Nutriroma, Hyderabad), Xanthan gum (Tapadia Marketing Services, Hyderabad), Tragacanth (Ranchhoddas Odhavji Gaglani \& Sons, Mumbai) were procured from standard food ingredient suppliers. Other ingredients such as wheat flour, fat, skim milk powder, lecithin and sugar were procured from the local market, Hyderabad.

\section{Preparation of raw materials}

Foxtail millet and quinoa were cleaned to remove foreign material and the grains were dehulled in an abrasive dehuller (Mathesis engineering Pvt. Ltd, Hyderabad) up to 17 percent removal of bran. The dehulled grain was then milled into flour in a pulveriser (Able manufacturers, Hyderabad) and sieved to get uniform particle size using mesh BSS No 60.

\section{Biscuits formulations}

Biscuit doughs were prepared from foxtail millet and quinoa with the addition of different combinations of hydrocolloids. Guar Gum (GG) and Xanthan Gum (XG) in FMB, Gum Tragacanth (TG) and XG in QAB, were incorporated at 1:1 ratio by replacing flour $(\mathrm{g} / 100 \mathrm{~g}$ on flour basis). Selection of hydrocolloids was based on previous studies (unpublished data from millet processing center, PJTS Agricultural University) which were considered as suitable for GF biscuits.

\section{Preparation of biscuits}

Initially, fat and sugar was creamed until fluffy, lecithin was then added and mixed again for a minute. Hydrocolloids were mixed with water to form a gel like consistency and the gel was added to the cream and mixed again, other dry ingredients were added followed by water and kneaded until the desired texture of the dough was obtained. The dough was sheeted with the help of a rolling pin. The biscuits were cut to round shape with the aid of biscuit cutter. Biscuits were baked in the oven (Kar Bakery equipments India Pvt. Ltd) at $170^{\circ} \mathrm{C}$ for 25 minutes.

\section{Sensory evaluation of Gluten free biscuits}

The sensory assessments were conducted in sensory evaluation laboratory. Semi trained panel members at Post Graduate and Research Centre, PJTSAU, Rajendranagar, Hyderabad, were selected as panelists for the study. They were given written instructions and asked to evaluate the products for acceptability in terms of color, texture, taste, flavor and overall acceptability using nine-point hedonic scale $(1=$ dislike extremely to $9=$ like extremely; as described by Meilgaard et al., (1999).

\section{Physical characteristics of Gluten free biscuits}

Physical quality characteristics like diameter, thickness and spread factor were determined according to the (AACC, 2000) method. Water absorption capacity (Mohsenin, 1986) was estimated by suspending ground biscuit in water at room temperature for $30 \mathrm{~min}$ by gently stirring and centrifuging for $15 \mathrm{~min}$. The resultant supernatant was decanted into an evaporated dish. WAC was calculated using the formula WAC $=$ Weight of sediment/Weight of dry solids. The Color quality of biscuits (Hunter Lab, 2013) was estimated by using Hunter lab calorimeter (Color Quest XE Hunter Lab, USA). Color lab scale values (CIE LAB scale) were determined by using hunter calorimeter. $\mathrm{L}^{*}$ 
indicates lightness and extends from 0.0 (black) to 100.0 (white). The other two coordinates $\mathrm{a}^{*}$ and $\mathrm{b}^{*}$ represent redness $\left(+a^{*}\right.$ value $)$ to greenness (-a*value) and yellowness $\left(+b^{*}\right.$ value) to blueness $\left(-b^{*}\right.$ value $)$.

\section{Nutritional analysis for selected biscuits}

The samples were estimated for their moisture (AOAC, 1990), protein (AOAC, 2005), carbohydrate, fat (AOAC, 1997), ash (AOAC, 2005), using standard methods. Total dietary fiber (TDF), soluble dietary fiber (SDF), insoluble dietary fiber (IDF) was determined by enzymatic gravimetric method (AOAC, 1995).

\section{Statistical analysis of the data}

All the results were statistically analyzed using STAT GRAPHICS centurion version 17.1.11. One way ANOVA technique was used to find out the significant effect of hydrocolloids on the quality parameters of gluten free biscuits (Snedecor and Cochran, 1994).

\section{Results and Discussion}

\section{Sensory quality characteristics of biscuits}

Significant effect was observed on the sensory attributes of gluten free biscuits due to hydrocolloids $(\mathrm{P}<0.05)$. The overall acceptability of biscuits ranged between 5.4 and 8.4. Wheat biscuits (WHB) scored highest among all sensory attributes when compared with that of made from foxtail millet flour (FMF) and quinoa flour (QAF). Incorporation of hydrocolloids to gluten free biscuits significantly improved their sensory characteristics $(\mathrm{P}<0.05)$. It is evident from the figure 1 that, quinoa biscuits $(\mathrm{QAB})$ received higher scores for color and texture, while foxtail millet biscuits (FMB) for taste and flavor. Addition of GG XG at $1 \%$ significantly improved the color, taste, texture and flavor of FMB relative to FMB control. In case of rice based gluten free bread $0.5 \%$ diacetyltartatic acid ester of mono- and diglycerides combined with $0.5 \%$ xanthan guar gum blend or xanthan locust bean gum blend provided the best bread, with good volume and crumb texture and the highest scores for texture acceptability. 0.5\% diacetyltartatic acid ester of mono- and diglycerides combined with $0.5 \%$ xanthan guar gum blend or xanthan locust bean gum blend provided the best bread, with good volume and crumb texture and the highest scores for texture acceptability (Mahmoud $e t$ al., 2013).

Similar effect of hydrocolloids was observed in quinoa which was indicated by the predominantly lower scores for the quinoa control biscuits. Panelists reported that biscuits with only QAF were darker in color and harder in texture when compared with biscuits made with hydrocolloids. The overall acceptability of biscuit without hydrocolloid was 5.4, which was significantly improved with addition of TG XG 1\% (8.3). Addition of hydrocolloids reduced hardness, darkness and improved taste in the biscuits. Variation in sensory scores might be due to different chemical structure and interaction between the hydrocolloids and food ingredients (Kaur et al., 2015). Significant effect of XG can be clearly observed in improving the overall acceptability of biscuits. Similar observations was reported by Kaur et al., (2015), they incorporated various hydrocolloids in buckwheat flour biscuits and reported that xanthan gum played a significant role in improving the color, taste, texture and overall acceptability of biscuits.

\section{Physico-chemical characteristics of biscuits}

The physico-chemical characteristics of all the biscuits were shown in table 1 . There was 
a significant difference in weight among all the biscuit variations $(\mathrm{P}<0.05)$. Mean weight of wheat biscuits was 10.12 whereas weights of gluten free biscuits ranged between 10.15 and 10.41. Biscuits prepared from foxtail millet and quinoa had more weight relative to WHB which might be due to the particle size and weights of the flours.

Addition of hydrocolloids improved the weight of the FMB (10.32) and QAB (10.41) significantly $(\mathrm{P}<0.05)$, similar increase in weight of Buck Wheat biscuits when compared to control WHB was observed by Kaur et al., (2015) and also reported that addition of hydrocolloids increased the weight of biscuits. Diameter of biscuits made from wheat $(62 \mathrm{~mm})$ was significantly higher compared to gluten free biscuits. Addition of hydrocolloids to the gluten free biscuits (FMB and $\mathrm{QAB}$ ) significantly affected the diameter with an increase. This suggests that application of hydrocolloids improved the diameter of gluten free biscuits. Kaur et al., (2015) reported that when hydrocolloids were added to buckwheat flour and they exhibited significant effect on biscuit diameter.

Significant difference was observed in the thickness of biscuits irrespective of the type of grain and hydrocolloids $(\mathrm{P}<0.05$, Table 1$)$. The thickness of WHB $(7.65 \mathrm{~mm})$ was higher than that of FMB $(7.41 \mathrm{~mm})$ as well as QAB (7.58mm) $\quad(\mathrm{P}<0.05)$ Addition of hydrocolloids increased the thickness of both the biscuits by $2.1 \%$ and $1.6 \%$ for FMB and QAB respectively. Adriana et al., (2015) blended rice flour and quinoa together in different concentrations i.e. rice flour: QAF, 90:10, 75:25 and 55:45 to prepare gluten free cookies and reported that increase in concentration of quinoa reduced the thickness from $9.8 \mathrm{~mm}$ to $9 \mathrm{~mm}$. Rajesh et al., (2015) reported that highest thickness was observed in sample treated with xanthan gum $(8.4 \mathrm{~mm})$ which was significantly higher than control biscuits made from refined wheat flour (WF) (7.8mm).

The spread ratio of biscuits made from wheat was significantly higher when compared to gluten free biscuits. Decrease in spread ratio was observed in both FMB and QAB when hydrocolloids were added which might be due to the differences in water binding capacity of the hydrocolloids employed (Rajesh et al., 2015). Spread ratios of biscuits ranged between 7.60 to 8.1. A higher consistency results in a reduced cookie spread, as cookie spread seems to be controlled by the dough viscosity; a lower viscosity allows the cookie to spread faster (Miller, 1997). Reduced spread ratio was reported by Rajesh et al., (2015); Kaur et al., (2015) in proso millet flour and buckwheat flour when hydrocolloids were added. Bulk density of QAB was significantly higher when compared with other biscuits (Table 1). WHB exhibited the bulk density of 0.70 followed by FMB. Addition of hydrocolloids did not show any significant difference in bulk density. The variations in the bulk density might be due to the difference in bulk density of different flours. Significant difference was observed in WAC of the biscuits $(\mathrm{P}<0.05$, Table 1$)$. Highest WAC was found in WHB (1.59) than gluten free biscuits. The WAC of FMB and QAB was found to be 1.48 and 1.44 respectively. Addition of hydrocolloids significantly improved the WAC to 1.58 and 1.56. WAC represents the ability of a product to associate with water under conditions where water is limiting (Singh, 2001). Different protein structures and the presence of different hydrophilic carbohydrates might be responsible for variations in the WAC. The increase in WAC when added hydrocolloids may be due to the presence of hydroxyl groups in the hydrocolloid structure that helps in the retention of higher quantity of water through hydrogen bonding (Rosell et al., 2001). 
Fig.1 Sensory attributes of gluten free $v s$ wheat biscuits

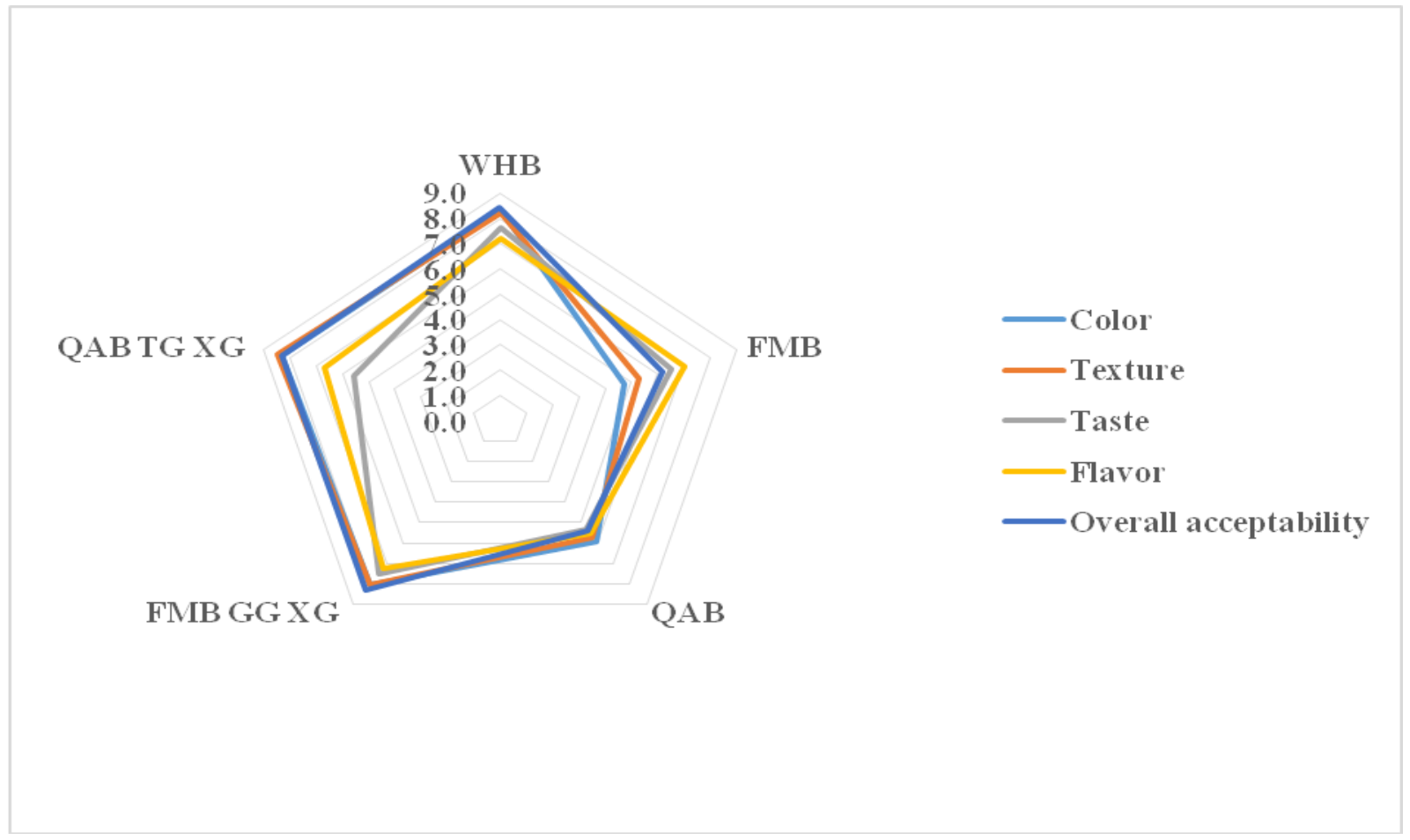

Fig.2 L*, a* $\mathrm{b}^{*}$ Values of the gluten free $v s$. wheat biscuits

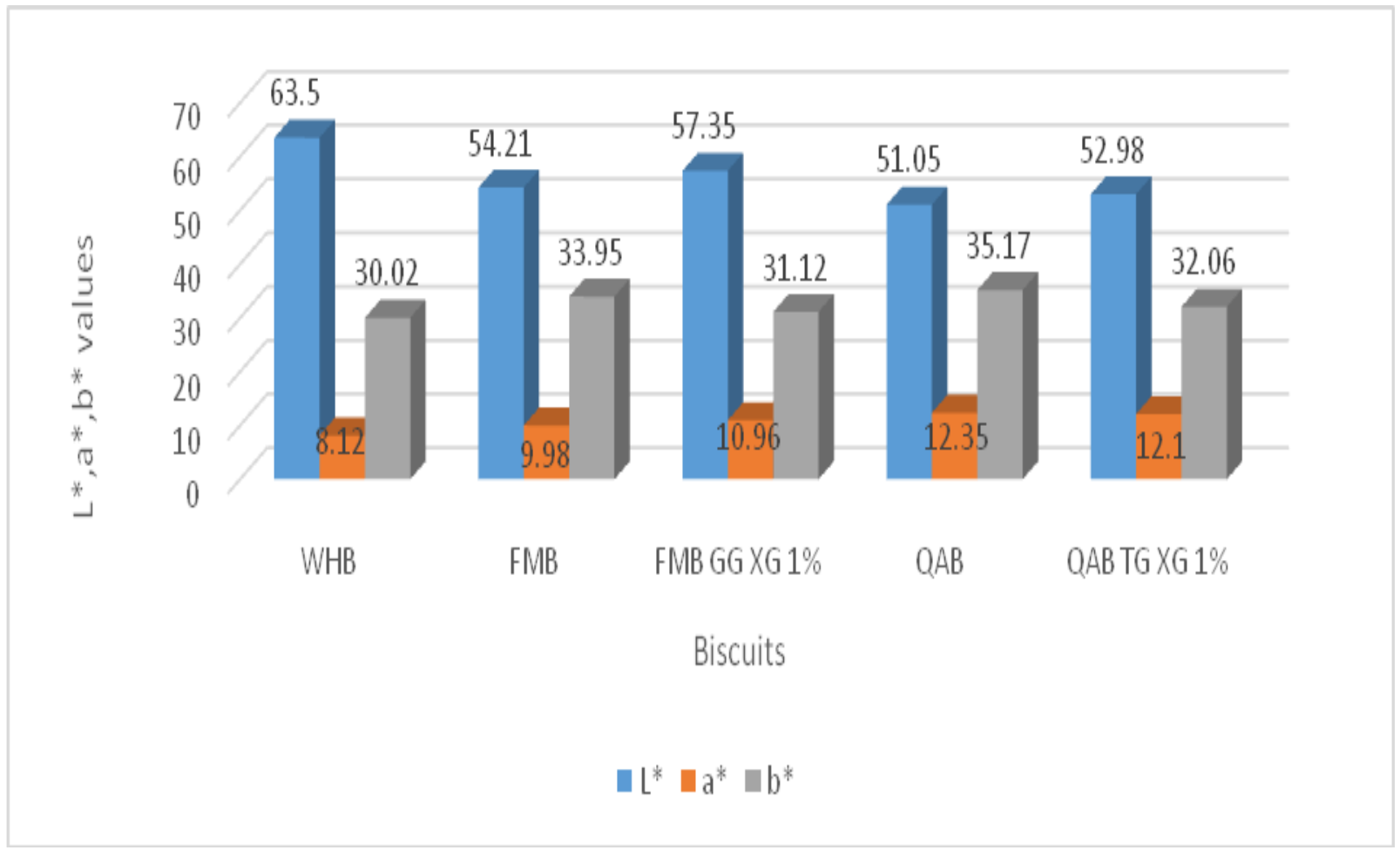


Table.1 Physical characteristics of gluten free biscuits $v s$. wheat biscuits*

\begin{tabular}{|l|c|c|c|c|c|}
\hline Parameter & WHB & FMB & FMB GG XG & QAB & QAB TG XG \\
\hline Weight $(\mathrm{g})$ & $10.12 \pm 0.01$ & $10.15 \pm 0.02$ & $10.32 \pm 0.05$ & $10.26 \pm 0.05$ & $10.41 \pm 0.11$ \\
\hline Diameter $(\mathrm{mm})$ & $62.00 \pm 0.02$ & $58.35 \pm 0.05$ & $59.13 \pm 0.08$ & $58.15 \pm 0.02$ & $59.00 \pm 0.15$ \\
\hline Thickness $(\mathrm{mm})$ & $7.65 \pm 0.01$ & $7.41 \pm 0.11$ & $7.57 \pm 0.10$ & $7.58 \pm 0.15$ & $7.70 \pm 0.14$ \\
\hline Spread ratio & $8.10 \pm 0.15$ & $7.87 \pm 0.19$ & $7.81 \pm 0.24$ & $7.67 \pm 0.18$ & $7.60 \pm 0.19$ \\
\hline Bulk density(g/cm3) & $0.70 \pm 0.11$ & $0.61 \pm 0.06$ & $0.61 \pm 0.12$ & $0.75 \pm 0.05$ & $0.75 \pm 0.02$ \\
\hline WAC (g/g) & $1.59 \pm 0.09$ & $1.48 \pm 0.04$ & $1.58 \pm 0.11$ & $1.44 \pm 0.06$ & $1.56 \pm 0.05$ \\
\hline
\end{tabular}

Mean values in the same row are significantly different with each other $(\mathrm{p}<0.05)$

Table.2 Nutrient composition (\%) of gluten free flours, biscuits $v s$. wheat flour and biscuits*

\begin{tabular}{|l|c|c|c|c|c|c|c|c|}
\hline & Moisture & Ash & Fat & Protein & \multicolumn{2}{|c|}{ Dietary Fiber } & Carbohydrates \\
\cline { 5 - 8 } & & & & & $T D F$ & $S F$ & $I S F$ \\
\hline WF & $11.49 \pm 0.05$ & $0.97 \pm 0.05$ & $1.98 \pm 0.11$ & $10.76 \pm 0.05$ & $10.29 \pm 0.02$ & $2.14 \pm 0.02$ & $8.15 \pm 0.06$ & $64.51 \pm 0.05$ \\
\hline FMF & $10.82 \pm 0.02$ & $1.01 \pm 0.07$ & $4.66 \pm 0.01$ & $14.03 \pm 0.05$ & $9.25 \pm 0.01$ & $2.31 \pm 0.01$ & $6.94 \pm 0.12$ & $60.23 \pm 0.18$ \\
\hline QAF & $11.00 \pm 0.01$ & $2.14 \pm 0.02$ & $6.50 \pm 0.02$ & $17.18 \pm 0.03$ & $15.58 \pm 0.02$ & $5.45 \pm 0.03$ & $10.18 \pm 0.04$ & $47.60 \pm 0.16$ \\
\hline WHB & $3.12 \pm 0.08$ & $0.13 \pm 0.08$ & $18.12 \pm 0.02$ & $5.70 \pm 0.01$ & $6.12 \pm 0.11$ & $1.02 \pm 0.02$ & $5.10 \pm 0.06$ & $66.80 \pm 0.15$ \\
\hline FMB & $3.59 \pm 0.05$ & $0.56 \pm 0.09$ & $21.94 \pm 0.01$ & $7.54 \pm 0.01$ & $7.86 \pm 0.12$ & $1.82 \pm 0.01$ & $6.04 \pm 0.05$ & $58.50 \pm 0.20$ \\
\hline FMB GG XG & $3.91 \pm 0.01$ & $0.56 \pm 0.11$ & $21.95 \pm 0.05$ & $7.55 \pm 0.04$ & $7.93 \pm 0.13$ & $2.05 \pm 0.02$ & $5.88 \pm 0.03$ & $58.09 \pm 0.15$ \\
\hline QAB & $3.25 \pm 0.02$ & $1.13 \pm 0.04$ & $24.24 \pm 0.03$ & $9.10 \pm 0.03^{\mathrm{a}}$ & $11.12 \pm 0.11$ & $3.90 \pm 0.11$ & $7.22 \pm 0.04$ & $51.16 \pm 0.11$ \\
\hline QAB TG XG & $3.65 \pm 0.05$ & $1.25 \pm 0.05$ & $24.43 \pm 0.02$ & $9.10 \pm 0.01^{\mathrm{a}}$ & $11.34 \pm 0.11$ & $3.50 \pm 0.02$ & $7.84 \pm 0.03$ & $50.23 \pm 0.12$ \\
\hline
\end{tabular}

Mean values in the same column are significantly similar with each other $(\mathrm{p}<0.05)$ 
The results are in agreement with Rajesh et al., (2015) who reported that addition of hydrocolloids to the proso millet flour improved the WAC, similarly Kaur et al., (2015) also reported that addition of hydrocolloids significantly improved the WAC of buckwheat flour.

\section{Color}

Significant effect of hydrocolloids was observed on $L^{*} a^{*} b^{*}$ values of the biscuits ( $<<0.05$, Fig. 2). WHB had highest $\mathrm{L}^{*}$ values followed by FMB with GG XG $1 \%$ and FMB without hydrocolloids. QAB had least $\mathrm{L}^{*}$ values, this might be due to the high protein content, sugars and phenolic compounds of formulations with higher proportions of QAF may have contributed to decrease the lightness values of the biscuits, due to the Maillard reaction, with a consequent increase of melanoidin formation, resulting in a darkening of the product (Secchi et al., 2011; Zucco et al., 2011; Bassinello et al., 2011; Singh et al., 2007). In addition, oxidation of phenolic compounds present in QAF consequent formation of dark pigments may also have interfered (Adelakun et al., 2012; Takata et al., 2007).

Isabelle et al., (2014) used QAF, quinoa flakes and corn starch to prepare cookies and reported that the $\mathrm{L}^{*}$ value ranged between 58 to 90 , and $\mathrm{L}^{*}$ value decreased with increase in QAF. Addition of hydrocolloids in both foxtail millet and QAB significantly improved the color values of biscuits. The $\mathrm{a}^{*}$ values ranged from 8.12 to 12.10 while $b^{*}$ value ranged from 30.02 to 32.06 . Highest $a^{*}$ value was observed in QAB without hydrocolloids and lowest in wheat biscuits. Highest $b^{*}$ value was observed in QAB without hydrocolloids (35.17) followed by Q.B TG XG 1\% (32.06), foxtail biscuits without hydrocolloids (33.95) F.B GG XG 1\% (31.12) and lowest in WHB (30.02).

\section{Nutrient composition of selected gluten free and wheat biscuits}

Significant difference in moisture was observed between all the variations irrespective of flours and biscuits $(\mathrm{P}<0.05)$.WF (11.49) exhibited highest moisture content when compared with gluten free flours (10.82 to 11) (Table 2). Moisture content of the gluten free biscuits ranged between 3.59 and 3.25 indicating good storage stability. Low moisture is a positive parameter related to crispness, an important desirable attribute in cookies (Canett-Romero et al., 2004). Among the biscuits high moisture content was observed in WHB followed by QAB and FMB which might be due to the difference in moisture content of flours and their interaction with other ingredients in biscuits. Sambavi et al., (2015) reported that moisture content of cookies made with $55 \%$ foxtail millet and $45 \%$ wheat flour was 4.6. Andriana et al., (2015) reported that that moisture content increased with increase in quinoa flour in biscuits made with quinoa and rice flour. Addition of hydrocolloids in the biscuits significantly increased the moisture content of FMB and QAB $(\mathrm{P}<0.05)$. Increased moisture contents for cakes prepared from wheat flour containing hydrocolloids have been reported by Ashwini et al., (2009). Rosell et al., (2001) reported an increase of water activity as well of moisture retention in bread made with wheat flour due to the higher water holding capacity of the hydrocolloids in contrast no significant effect of hydrocolloids was reported Lazaridou et al., (2007) in gluten free bread made with rice flour. Ash content of gluten free flours (1.01 to 2.14 and biscuits (0.16 to 1.25$)$ was significantly higher than wheat flour (0.97) and biscuits (0.13) (Table 2 ), which indicates the high mineral content. Addition of hydrocolloids significantly $(p<0.05)$ increased the ash content of the $\mathrm{QAB}$ and no significant difference was 
observed in FMB. Kaur et al., 2015 also reported similar observation of increase in ash content when hydrocolloids were added. The increased ash content with the addition of gums may be due to the mineral content present in the hydrocolloids (Alobo, 2003).

Significant difference was observed among the TDF content of all the variations irrespective of flours and grain as shown in table 2. Mean TDF of gluten free flours (12.41) were much higher than wheat four (3.19). QAF and FMF has significantly very high amount of TDF when compared with WF. Accordingly, in biscuits QAB had higher TDF (11.12) when compared with that of FMB (7.86) and with that of WHB (6.12). Addition of hydrocolloids significantly improved the TDF of the biscuits which might be due to the fiber content of hydrocolloids. Very difference in the TDF was found between WHB and QAB.

It can be observed from table 2 that there was an increase of TDF due to application of hydrocolloids by $0.89 \%$ and $1.98 \%$ in FMB and QAB respectively. The SF content of flour ranged between 2.14 and 5.45 with significant difference, wheat flour had significantly lower SF when compared with FMF and QAF. Similarly, in biscuits also it ranged between 1.02 and 3.9 with highest in quinoa with hydrocolloids followed by quinoa without hydrocolloids and FMB and least in wheat biscuits. Addition of hydrocolloids increased SF in FMB by $12.6 \%$, while it was decreased by $10.2 \%$. Significant difference was observed in ISF content of the flours and biscuits.

With respect to, the mean ISF content of was 8.56 and 2.31 in gluten free flours and WF respectively, while it was6.74 in gluten free biscuits and 1.71 in WHB. Protein content was significantly higher in gluten free biscuits than WHB $(\mathrm{P}<0.05$, Table 2$)$. Mean protein content of gluten free flours was 15.60 and 8.33 in gluten free biscuits which was significantly $(\mathrm{p}<0.05)$ higher than WF $(10.76)$ and WHB (5.7). Lorenz et al., (1991) also reported that quinoa had high protein content when compared with wheat flour. According to FAO, (2011); 100 grams of quinoa contains nearly fivefold lysine, more than double isoleucine, methionine, phenylalanine, threonine, valine, and much larger amounts of leucine (all essential amino acids along with tryptophan) than 100 grams of wheat. In addition it also exceeds wheat, in s some cases by the triple, in the amounts of histidine, arginine, alanine and glycine as well as containing amino acids not present in wheat such as proline, aspartic acid, glutamic acid, cysteine, serine and tyrosine (all nonessential amino acids).

Quinoa due to its high content of essential amino acids in its protein, quinoa is considered the only plant food that provides all essential amino acids, which are extremely close to human nutrition standards established by the FAO. Addition of hydrocolloids did not significantly affect the protein content of biscuits. Sambavi et al., (2015) made biscuits with FMF and wheat flour by adding in different concentrations and reported that the protein content of biscuits was 13.10 when $55 \%$ wheat flour and $45 \%$ FMF.

Andriana et al., (2015) added QAF and rice flour in different concentrations to make biscuits and reported that protein content increased with the increase in QAF. Highest fat content was observed in QAF (6.50) followed by FMF (4.66) and WF (1.98).

Similarly, high fat content was observed in QAB (24.24) followed by foxtail biscuits (21.94) and least in WHB (18.12) \% (Table 2). Compared to the wheat biscuits, GF biscuits were found to have higher fat content, which can be attributed to the fat content of 
the their respective flours, however the fats present in these grains are rich in health promoting fatty acids such as omega 3 fatty acids and omega 6 fatty acids. Omar (2016) reported that quinoa based extrudates had $58 \%$ of Linoleic acid, Oleic acid, $4.47 \%$ of $\alpha$ linolenic acid. Zhang et al., 2015 reported that foxtail millet contains Linoleic acid (66.68\%), Oleic acid $(16.11 \%)$, palmitic acid $(7.42 \%)$, stearic acid (6.84\%) and linolenic acid $(2.48 \%)$. Further, addition of hydrocolloids did not have any significant effect on fat content of the biscuits. Highest carbohydrate content was found in WF when compared with gluten free flours. Similarly, in biscuits also highest carbohydrate content was found in WHB (66.8) followed by FMB (58.5) and least in QAB (51.16). CHO content was significantly higher in biscuits when compared with flours, which is due to addition of various ingredients in biscuits making process. Addition of hydrocolloids significantly increased the carbohydrate content (Table 2) which can be attributed to the non-starchy carbohydrates present in hydrocolloids, which are of health benefiting components.

In conclusion, Combination of $\mathrm{GG} X \mathrm{XG}$ and TG XG at $1 \%$ concentration found to be beneficial in the development of GF biscuits from nutrient dense quinoa and foxtail millet. These biscuits are much superior to the commercial GF biscuits which are generally prepared from high starch, fat and sugar. Consumption of these biscuits are not only suitable for celiac and gluten intolerant people but can also become a good choice of biscuit for many with life style diseases, due to their rich dietary fiber content and other phytochemical components. However clinical studies can confirm these benefits.

\section{References}

AACC. 2000. Approved Methods of the American Association of Cereal
Chemists. $10^{\text {th }}$ Edition.St Paul Minnesota, MN. USA.

Adelakun, O.E., Kudanga, T., Parker, A. 2012. Laccase-catalyzed dimerization of ferulic acid amplifies antioxidant activity. Journal of Molecular Catalysis B. Enzyme. 7:29-35

Adriana, P., Simona, M., Sevastiţa, M., Anamaria, P. 2015. Effect of quinoa flour addition on quality characteristics of rice gluten-free cookies. Journal of Agroalimentary Processes and Technologies. 21(4): 371-378

Alobo, A.P. 2003. Proximate composition and selected functional properties of defatted papaya kernel flour. Plant Food for Human Nutrition, 58: 1-7.

AOAC. 1981. Official Methods of Analysis for fat and carbohydrate. Association of Official Analytical Chemists. $13^{\text {th }}$ Edition. Washington, DC.

AOAC. 1984. Official Methods of Analysis for ash. Association of Official Analytical Chemists. $14^{\text {th }}$ Edition. Washington, DC.

AOAC. 2005. Official Methods of Analysis for protein. Association of Official Analytical Chemists. $18^{\text {th }}$ Edition.Arlington V A 2209, USA. AOAC 984.13.

AOAC.1990. Official Methods of Analysis for moisture. Association of Official Analytical Chemists. $14^{\text {th }}$ Edition. Washington, DC.

AOAC.1995. Official Methods of Analysis for Dietary fibre, soluble dietary fiber and insoluble dietary fibre. Association of Official Analytical Chemists. $14^{\text {th }}$ Edition. Washington, DC.

AOAC. 1995. Official methods of analysis (Association of Official Analytical Chemists. 16th edition. Washington, DC.

Ashwini, A., Jyotsna, R., and Indrani, D. 2009. Effect of hydrocolloids and emulsifiers on the rheological, microstructural and quality characteristics of eggless cake. Food Hydrocolloids, 23, 700-707.

Bassinello, P.Z., Freitas, DGC, Ascheri, JL. 2011. Characterization of cookies formulated with rice and black bean extruded flours. Procedia Food Science. 


\section{$1: 1645-1652$}

Canett-Romero R., Ledesma-Osuna AL., Robles, SRM, Morales, CR., LeónMartínez L, Leon-Galvez, R. 2004. Characterization of cookies made with deseeded grape pomace. Archivos Latinoamericanos de Nutricion. 54: 9399

FAO (Food and Agriculture organization), 2011. Quinoa: An ancient crop to contribute to world food security

Gallagher, E. 2002. The application of functional ingredients in short dough biscuits. (Master's thesis). Department of Food Technology, University College Cork, Cork, Ireland.

Goudar, G., Hemalatha, S., Naik, R. K. and Kamatar, M. Y., 2011, Evaluation of nutritional composition of foxtail millet (Setaria italic) grains cultivated in agro climatic zones of Karnataka by NIR. Paper presented in: National Symp. Recapturing Nutritious millets for Health and Management of Diseases, UAS, Dharwad. 16-17. 37.

Hunterlab. 2013. Hunter Associate Laboratory. Manual version-2.1. 60: 1014-593.

Isabelle, L., Brito, Evandro, LDS, Suenia SSF, Marta, SM., Fabio, Yamashita, Marciane, M. 2015. Nutritional and sensory characteristics of gluten-free quinoa (Chenopodium quinoa Willd)-based cookies development using an experimental mixture design. Journal of Food Science and Technology. 52(9): 5866-5873.

Kaur, M., Kawalji, S.S., AmitPal, A., Aruna, S.2015. Gluten free biscuits prepared from buckwheat flour by incorporation of various gums: Physicochemical and sensory properties. LWT - Food Science and Technology. 62: 628-632.

Lazaridou, A., Duta, D., Papageorgiou, M., Belc, N., Biliaderis, C.G. 2007. Effects of hydrocolloids on dough rheology and bread quality parameters in Gluten-free formulations. Journal of Food Engineering. 79: 1033-1047.

Lorenz, K., Coulter, L. 1991. Quinoa flour in baked products. Plant Foods for Human Nutrition 41: 213-223.

Mahmoud, R. M., Yousif, E. I., Gadallah, M. G. E., and Alawneh, A. R. 2013. Formulations and quality characterization of gluten-free Egyptian balady flat bread. Annals of Agricultural Science, 58: 19-25.

Malleshi, N.G. 1986. Processing of small millets forfood and industrial uses. In: Small Millets in Global Agriculture (Eds) A. Seetharam, K.W. Riley and G. Hari Narayana). New Delhi: Oxford and IBH Publishing Company: 325-339

Mariotti, M., Lucisano, M., Pagani, M. A and Perry, K. 2009. The role of corn starch, amaranth flour, pea isolate, and Psyllium flour on the rheological properties and the ultrastructure of gluten-free doughs. Food Research International, 42: 963-975.

Meilgaard, M., Civille, G.V and Carr, B.T. 1999. Sensory Evaluation Techniques. Third edition. CRC Press. Boca Raton.

Miller, RA. 1997. Factors in hard wheat flour responsible for reduced cookie spread. Cereal Chemistry. 74: 330-336.

Mohsenin, N.N. 1986. Physical properties of plant and animal materials. Gordon and breach Science Publishers, New York. 2: 79-337.

Omar. 2016. Quality Evaluation of Extruded Snacks Prepared from Quinoa Blended with Different Starchy Ingredients. Masters thesis. Professor JayaShankar Telangana state Agriculture University. Hyderabad.

Rai, S., Amarjeet Kaur and Baljit Singh 2011. Quality characteristics of gluten free cookies prepared from different flour combinations. Journal of Food Science and Technology. doi: 10.1007/s13197011-0547-1.

Rajesh, D., R. Ravi, R., Bhattacharya, S. 2015. Effect of Hydrocolloids on Quality of Proso Millet Cookie. Food Bioprocess Technology. 8: 2298-2308.

Rosell, C. M., Rojas, A.J. and Benedito. 2001. Influence of Hydrocolloids on dough rheology and bread quality. Journal of Food Hydrocolloids. 15: 75-81. 
Sambavi,A., Sabaragamuwa, R.S., Suthakaran, R.2105. Development of Cookies Using A Combination Of Foxtail Millet And Wheat Flours. International Journal of Scientific and Technology Research. 4(10): 294-295.

Saturni, L., Gianna Ferretti and TizianaBacchetti. 2010. The Gluten-Free Diet: Safety and Nutritional Quality. Nutrients. $\quad 2$ : $\quad 16-34 ; \quad$ doi: 10.3390/nu2010016

Schober, T.J., O'Brien C.M., McCarthy, D., Darnedde, A., Arendt, E.K. 2003. Influence of gluten-free flour mixes and fat powders on the quality of gluten-free biscuits. European Food Research and Technology. 216: 369-376

Schuppan, D., Junker, Y., and Barisani, D. 2009. Celiac disease: from pathogenesis to novel therapies. Gastroenterology, 137: 1912-1933.

Secchi, N., Stara, G., Anedda, R. 2011. Effectiveness of sweet ovine whey powder in increasing the shelf life of Amaretti cookies. LWT Food Science and Technology. 44:1073-1078

Sedecor, G.W and Cochran, W.G. 1980. Statistical Methods, Seventh Edition. Ames: Iowa State University Press.

Sharadanat, R., and Khan, K. 2003. Effect of hydrophilic gums on frozen dough. II. Bread characteristics. Cereal Chemistry. 80:773-780.

Singh, K. P., Mishra, H. N. and Saha, S. 2010. Moisture-dependent properties of barnyard millet grain and kernel. Journal of Food Engineering. 96: 598-606.

Singh, M., Mohamed, A. 2007. Influence of gluten-soy protein blends on the quality of reduced carbohydrates cookies. Food Science and Technology. 40: 353-360

Takata, K., Yanaka, M., Fujita, Y., Ishikawa, N. 2007. Evaluation of the grain and flour quality in near-isogenic wheat lines with waxy and doublenullWx proteins. Breeding Science. 57:79-83

Thathola, A., \& Sarita S. 2010. Suitability of Foxtail Millet (Setariaitalica) and Barnyard Millet (Echinochloa frumentacea) for Development of Low Glycemic Index Biscuits. Malasiyan journal of nutrition. 16(3):361-368.

Thompson, T. 2000. Folate, iron, and dietary fiber contents of the gluten free diet. Journal of American Dieteic Association.100: 1389-1396.

Vandana, S., Subhash, C., Pradeep, D., Makarand P. 2015.Quinoa (Chenopodium quinoa Willd.): A Nutritional Healthy Grain. International Journal of Advanced Research. 3(9): 725 - 736

Xue, J., and Ngadi, M. 2009. Effects of methylcellulose, xanthan gum and carboxymethyl cellulose on thermal properties of batter systems formulated with different flour combinations. Food Hydrocolloids 23: 286-295.

Zhang, A., Xiaodong, L., Guirong, W., Huijun, Jingke, L., Wei, Z., and Yuzong, Z. 2015. Crude Fat Content and Fatty Acid Profile and Their Correlations in Foxtail Millet. Cereal Chemistry. 92(5): 445.

Zucco, F., Borsuk, Y., Arntfield, SD. 2011. Physical and nutritional evaluation of wheat cookies supplemented with pulse flours of different particle sizes. $L W T$ Food Science and Technology. 44:20702076

\section{How to cite this article:}

Thejasri, V., T.V. Hymavathi, T.P. Pradeepa Roberts, B. Anusha and Suchiritha Devi, S. 2017. Sensory, Physico-Chemical and Nutritional Properties of Gluten Free Biscuits Formulated with Quinoa (Chenopodium quinoa Willd.), Foxtail Millet (Setaria italica.) and Hydrocolloids. Int.J.Curr.Microbiol.App.Sci. 6(8): 1710-1721. doi: https://doi.org/10.20546/ijcmas.2017.608.205 